\title{
Optical Parametric Technology for Methane Measurements
}

\author{
Martha Dawsey ${ }^{1 *}$ \\ Kenji Numata ${ }^{2}$ \\ Stewart $\mathrm{Wu}^{1}$ \\ Haris Riris ${ }^{1}$ \\ ${ }^{1}$ NASA- Goddard Space Flight Center, Greenbelt, MD 20771, USA \\ ${ }^{2}$ Department of Astronomy, University of Maryland, College Park, MD 20742, USA \\ *Corresponding author: martha.w.dawsey@nasa.gov
}

\begin{abstract}
Atmospheric methane $\left(\mathrm{CH}_{4}\right)$ is the second most important anthropogenic greenhouse gas, with approximately 25 times the radiative forcing of carbon dioxide $\left(\mathrm{CO}_{2}\right)$ per molecule. Yet, lack of understanding of the processes that control $\mathrm{CH}_{4}$ sources and sinks and its potential release from stored carbon reservoirs contributes significant uncertainty to our knowledge of the interaction between carbon cycle and climate change.

At Goddard Space Flight Center (GSFC) we have been developing the technology needed to remotely measure CH4 from orbit. Our concept for a $\mathrm{CH}_{4}$ lidar is a nadir viewing instrument that uses the strong laser echoes from the Earth's surface to measure $\mathrm{CH}_{4}$. The instrument uses a tunable, narrow-frequency light source and photon-sensitive detector to make continuous measurements from orbit, in sunlight and darkness, at all latitudes and can be relatively immune to errors introduced by scattering from clouds and aerosols.

Our measurement technique uses Integrated Path Differential Absorption (IPDA), which measures the absorption of laser pulses by a trace gas when tuned to a wavelength coincident with an absorption line. We have already demonstrated ground-based and airborne $\mathrm{CH}_{4}$ detection using Optical Parametric Amplifiers (OPA) at $1651 \mathrm{~nm}$ using a laser with approximately $10 \mu \mathrm{J} /$ pulse at $5 \mathrm{kHz}$ with a narrow linewidth. Next, we will upgrade our OPO system to add several more wavelengths in preparation for our September 2015 airborne campaign, and expect that these upgrades will enable $\mathrm{CH} 4$ measurements with $1 \%$ precision $(10-20 \mathrm{ppb})$.
\end{abstract}

Keywords: lidar, laser radar, methane, IPDA, optical parametric oscillator, optical parametric amplifier, OPO, OPA.

\section{INTRODUCTION}

The last report by the Intergovernmental Panel on Climate Change (IPCC) ${ }^{1}$ attributes the increase of the atmospheric concentrations of greenhouse gases above their preindustrial levels to the burning of fossil fuels and other anthropogenic sources. As the concentration of greenhouse gases steadily increases, the subsequent radiative forcing will likely have a significant impact on Earth's climate. Presently our knowledge and understanding of the important processes controlling greenhouse gas concentrations is incomplete. Current observations of greenhouse gases are mostly from in situ sites (surface and tower), airborne platforms, and space-based passive spectrometers. Initial space measurements of methane and other greenhouse gases came from SCIAMACHY on European Space Agency's (ESA's) environmental satellite (ENVISAT) mission ${ }^{2-4}$, the infrared atmospheric sounding interferometer (IASI) on the Centre 
National d'Etudes Spatiales's (CNES) MetOp satellite ${ }^{5-6}$, and NASA's atmospheric infrared sounder (AIRS) on that agency's Aqua Mission ${ }^{7-8}$. Additional space measurements are now available from Japan Aerospace Exploration Agency or Japan Space Exploration Agency's (JAXA's) greenhouse gases observing satellite (GOSAT) mission, which was launched in $2009^{9-12}$. All four instruments are passive spectrometers, and their observations are limited. Measurements using surface reflected sunlight by GOSAT and SCIAMACHY are limited to the sunlit areas of earth, and their data products are significantly affected by atmospheric scattering and the presence of clouds ${ }^{13-14}$; measurements in thermal infrared by AIRS and IASI have a measurement weighting function peaked in the mid-troposphere ${ }^{15}$ and are not sensitive to the sources and sinks of greenhouse gases at the surface but are very sensitive to atmospheric temperature changes.

Methane is a very important greenhouse gas because its radiative forcing is approximately 23 times larger per molecule than $\mathrm{CO}_{2}{ }^{1}$, and the methane mixing ratio is increasing along with $\mathrm{CO}_{2}{ }^{15-16}$. Anthropogenic sources of methane include fossil fuel production, rice farming, livestock, and landfills, while natural sources include wetlands, wild fires, and termites ${ }^{17}$. Oxidation by hydroxyl radicals in the atmosphere and oxidation by nonsaturated soils both serve as important sinks for methane. Additionally, there are large reservoirs of methane in the form of methane hydrates ${ }^{18}$ that are contained in the continental shelf with large reservoirs of carbon in the permafrost regions of Siberia, North America, and Europe. These are of major concern, because as global temperatures rise and the permafrost thaws, some of this carbon will be converted to methane and released into the atmosphere ${ }^{19-20}$. In order to have a better understanding of the global impact of this methane, a better understanding of methane distribution and its sources and sinks is imperative ${ }^{21-23}$.

To address this need for a better understanding of greenhouse gases, there is a call for NASA to implement active $\mathrm{CO}_{2}$ sensing from a space-based platform, currently called Active Sensing of $\mathrm{CO}_{2}$ Emissions over Nights, Days, and Seasons (ASCENDS). Included in this call is a statement that "If appropriate and cost-effective methane technology becomes available, methane capability should be added" to the ASCENDS mission ${ }^{24}$. To address this call at Goddard Space Flight Center (GSFC), we have developed lidar technology based on optical parametric generation (OPG) devices that can be used to measure methane remotely from a space-based platform. This technology has been demonstrated in ground measurements of methane, carbon monoxide, carbon dioxide, and water vapor ${ }^{25-26}$. In 2011 this technology was demonstrated on an airborne platform over California at altitudes from 3 to $11 \mathrm{~km}$. Additional airborne demonstrations of the optical parametric techniques are planned for September 2015.

\section{METHANE SPECTROSCOPY}

The strongest absorption bands for methane are at 1.65, 2.2,3.3, and $7.8 \mu \mathrm{m}$, with the line at $3.3 \mu \mathrm{m}$ being ideal for making high-sensitivity measurements of methane in low-pressure planetary atmospheres, such as that on Mars. The low pressure on Mars essentially Doppler broadens the absorption lines, allowing measurements by a laser spectrometer with sufficient signal-to-noise ratio (SNR) and high spectral resolution. This $3.3 \mu \mathrm{m}$ absorption line is also well suited for low altitude applications, such as pipeline leak detection ${ }^{27-30}$, or in-situ detection ${ }^{31-33}$.

However, in the Earth's atmosphere the absorption lines at $3.3 \mu \mathrm{m}$ are too strong for an active space-based sensing platform, because they would simply absorb all of the laser radiation before it reached the ground. Additionally, there are adjacent water vapor absorption lines that would cause significant interference in the signal, but are also highly variable, which would make an accurate measurement from space at $3.3 \mu \mathrm{m}$ very challenging.

The methane absorption line at $1.65 \mu \mathrm{m}$ is well suited for an active space-based sensing platform, for several reasons. Partially because it is almost two orders of magnitude weaker than the line at $3.3 \mu \mathrm{m}$, but also because this spectral region is relatively free of interference from other absorption lines, as seen in Figure 1. For these reasons, the methane absorption lidar at GSFC has chosen to focus on this spectral region. 


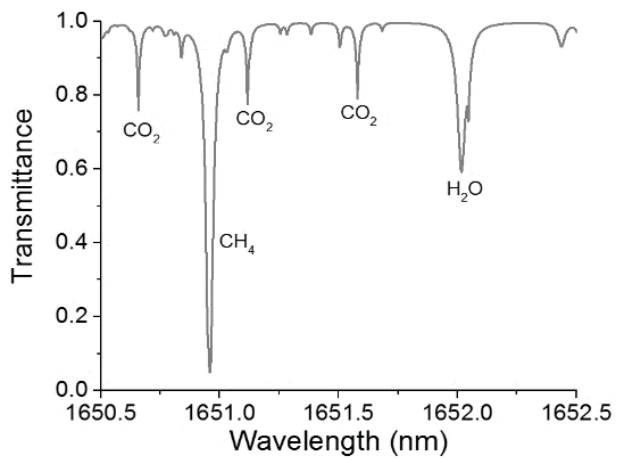

Figure 1. Atmospheric transmission for US standard atmosphere at $1650-1653 \mathrm{~nm}$ from $400 \mathrm{~km}$.

\section{LIDAR TECHNIQUE}

We have developed a direct-detection lidar to measure column methane abundance using the integrated path differential absorption (IPDA) technique. It uses a rapidly tuned pulsed laser, scanned across a selected methane absorption line, with a time-resolved receiver using a sensitive detector. Theoretically, only two wavelengths are necessary for this technique ("on" and "off" the absorption line), but in practice, additional wavelengths in conjunction with the line shape has proven to be quite valuable. The additional data allows solving for instrumental and systematic errors, such as etalon fringes with various periods and baseline drifts. In 2011, the system was scanned across 20 wavelengths distributed evenly across the $1651 \mathrm{~nm}$ absorption line. A laser transmitter for this system must have high enough pulse energy and a narrow enough spectral linewidth at the spectral absorption line ${ }^{34-36}$. Because they have sufficient wavelength tuning range and energy, even at wavelengths where traditional laser gain media do not work, optical parametric generation (OPG) devices are ideal for this application. The IPDA lidar transmitter in this effort has three major components as shown in Figure 2: 1) a seed laser, 2) a pump laser, and 3) an OPG device that will generate/amplify the tunable laser radiation at $\sim 1651 \mathrm{~nm}$.

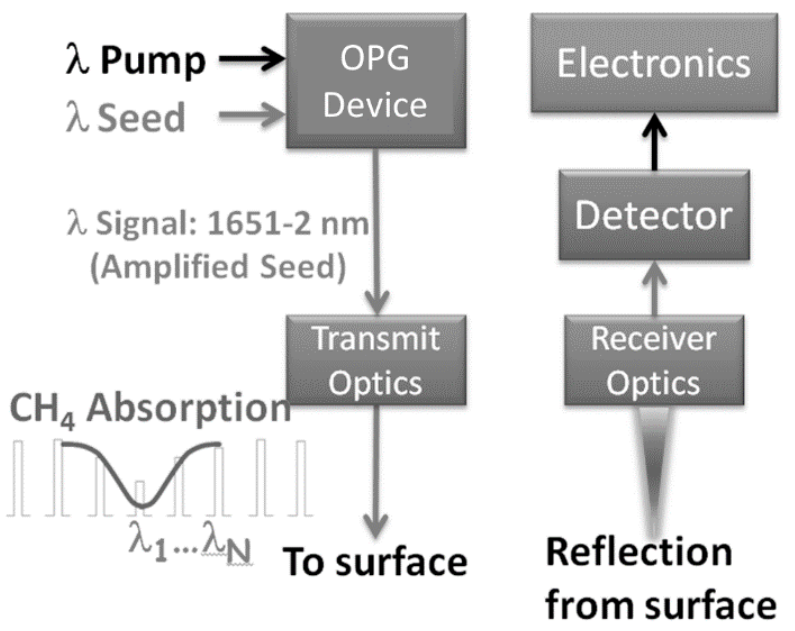

Figure 2. High level functional block diagram of the IPDA Methane Lidar.

\section{LASER TECHNIQUE}

In an OPG device, a nonlinear optical crystal is used to divide an incident laser pulse (or pump) into two photons: a signal and an idler. The wavelengths of the signal and the idler photons must satisfy the energy and the phase matching conditions in the crystal. Two OPG techniques are investigated: an optical parametric amplifier (OPA), and an 
optical parametric oscillator (OPO). The OPA was built and demonstrated in the airborne test flights in 2011 over California. For the 2015 test flights, both the OPA and an OPO will be flown.

\subsection{OPA}

An OPA is a seeded version of optical parametric generation, and a simplified block diagram of the OPA based lidar is shown in Figure 3. A pulse single-frequency $1064 \mathrm{~nm} \mathrm{Nd:YAG} \mathrm{laser} \mathrm{(pump)} \mathrm{and} \mathrm{a} \mathrm{continuous-wave} \mathrm{(CW)}$ $1651 \mathrm{~nm}$ distributed feedback (DFB) laser diode (seed) are used to pump the nonlinear periodically poled lithium niobate (PPLN) crystal. The laser diode can be used to adjust the wavelength of the seed laser; here it is used at $1578 \mathrm{~nm}$ to generate an idler wavelength at $3.3 \mu \mathrm{m}$ and $1651 \mathrm{~nm}$, which amplifies the seed wavelength. In principle, any diode laser between 1530 and $1660 \mathrm{~nm}$ can be used as a seed in order to target different trace gases in the 1.5-1.65 $\mu \mathrm{m}$ and 3-4 $\mu \mathrm{m}$ range.

Diode lasers are ideal for this application, because they are small, rugged, and have desirable spectroscopic characteristics. Their side mode suppression ratio typically exceeds $40 \mathrm{~dB}$, and they tune smoothly over a few nanometers. Additional advantages are that their wavelength can be tightly controlled via the temperature and current to the diode, the instantaneous linewidth can be less than $1 \mathrm{MHz}$, and they can be frequency stabilized using an external reference cell ${ }^{37}$.

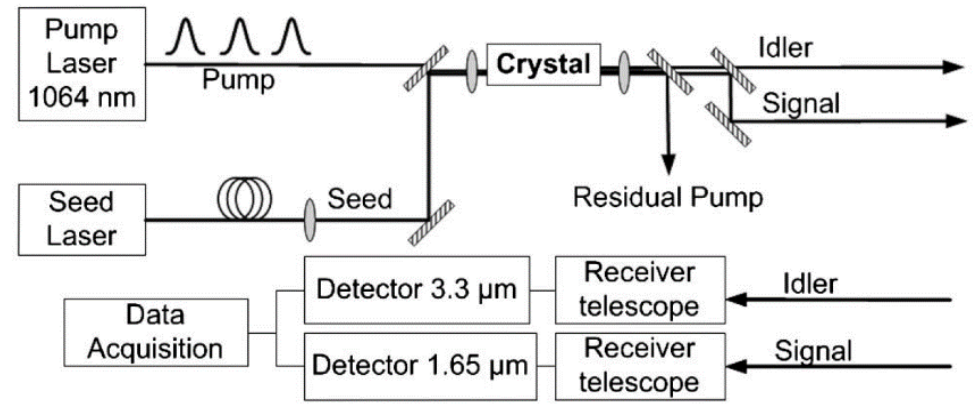

Figure 3. A simplified block diagram of the OPA based lidar flown in 2011.

In this system, the pump and the seed lasers are co-aligned and focused through the PPLN crystal. In order to optimize the phase matching at the target wavelength, the temperature of the crystal is varied from $70^{\circ}$ to $170^{\circ} \mathrm{C}$. The beam that is output from the crystal is then separated into three beam paths using dichroic mirrors (the idler, the signal, and the residual pump) so that each path has a different wavelength. At this point, the idler or the signal or both, can be used for trace gas detection, depending on the application. In the system shown in Figure 3, backscattered photons from both $1.651 \mu \mathrm{m}$ and $3.3 \mu \mathrm{m}$ are collected by receiver telescopes and detected by InGaAs and $\mathrm{HgCdZnTe}$ detectors.

\subsection{OPO}

The OPO built at GSFC is a parametric oscillator that uses a pulsed single-frequency 1064 Nd:YAG laser (pump) with a magnesium oxide-doped PPLN nonlinear crystal in a ring cavity. The master laser is frequency locked to the center of the reference methane absorption line at $1651 \mathrm{~nm}$, and the length of the OPO cavity is controlled to maintain the resonance of the master laser within the cavity. The slave laser is offset phase-locked to the master laser, and the beatnote between the two is detected and used to maintain a constant integer frequency offset of free spectral ranges (FSR) of the OPO cavity. These loops ensure that the OPO cavity length is stabilized against the target methane line, while both seed lasers transmit through the OPO cavity. The two lasers are fast switched by an electro-optical switch and then injected into the OPO cavity as seed lasers. The pump laser generates a $1.064 \mu \mathrm{m}$ pump pulse, whose timing is synchronized to the optical switching of the OPO seeds. An experimental setup is shown in Figure 4. 


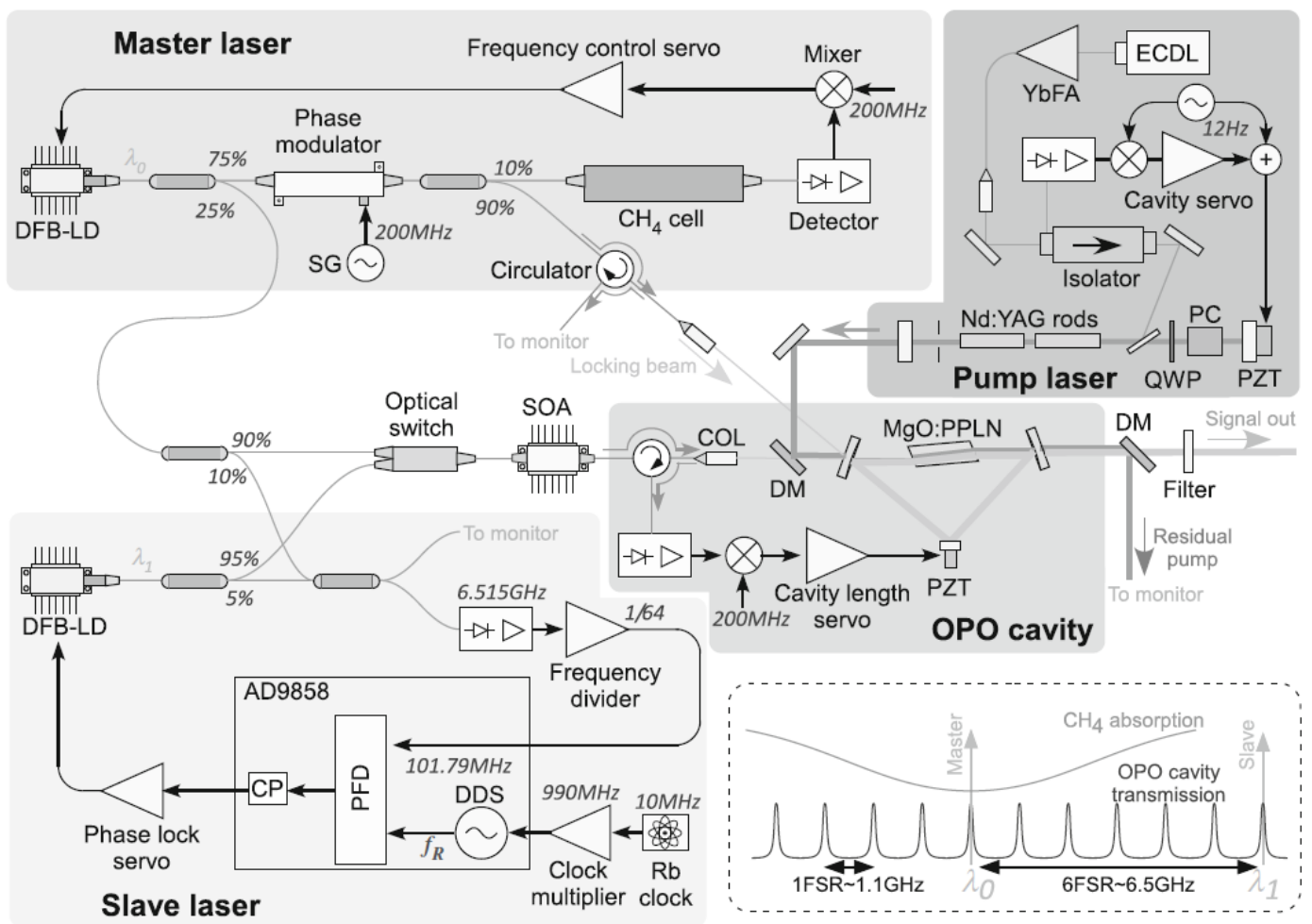

Figure 4. Experimental setup of the Methane lidar transmitter based on an OPO. The inset on the lower right shows the concept of the setup.

The OPO built at GSFC has a narrower linewidth than the OPA, because it is narrowed by the optical feedback within the cavity, which is an advantage for the IPDA lidar technique. Additionally, it differs from other OPO systems in its control scheme and its high repetition rate $(5 \mathrm{kHz})^{38-40}$. The higher repetition rate has been adopted for the ASCENDS mission in order to ensure overlap in the beam spots. The OPO used in this system does not require dynamic pulse-to-pulse adjustment, which is accomplished by combining an absolute frequency-locking technique, an optical phase-lock loop (OPLL), a phase modulation technique to lock the cavity length, and a fast electro-optical switch.

An open path demonstration of the OPO has been successfully completed, and additional specifications and results are detailed in Numata, et $a l^{41}$. Our current work includes incorporating 2 to 6 additional wavelengths to the existing laser transmitter, and scaling the laser transmitter energy to $\sim 300 \mu \mathrm{J}$. This system will be flown in an airborne demonstrator in the fall of 2015.

\section{FLIGHT CONFIGURATION AND RESULTS FROM 2011}

In August of 2011, the OPA laser $(\sim 10 \mu \mathrm{J}$ at $1651 \mathrm{~nm})$ was used in the transmitter of the airborne methane absorption lidar demonstrated using NASA's DC-8 aircraft, based at Dryden Airborne Operations Facility (DAOF) in Palmdale, California. Three flights occurred over California's Central Valley, all of which traversed similar paths with similar flight times (2.5 hours) and similar stepped altitudes (3, 4.8, 6.2, 7.9, 9.5, and $11.1 \mathrm{~km})$.

The receiver telescope is a $20 \mathrm{~cm}$ diameter commercial telescope (Vixen VC200L), and the light is then coupled into an AR coated $600 \mu \mathrm{m}$ fiber (Fiberguide CB18167). The receiver field-of-view (FOV) is $300 \mu \mathrm{rad}$, as determined by the receiver fiber core size, its numerical aperture, and the effective focal length of the telescope. The receiver fiber output is collimated and directed through a narrow bandpass filter $(0.8 \mathrm{~nm}$, from Barr Associates), an iris, and then onto the detector. The detector used in 2011 is a photon counting Hamamatsu photomultiplier tube (PMT), with a quantum efficiency of $1 \%$ at $1651 \mathrm{~nm}$, along with a high-speed amplifier. A field-programmable gate array (FPGA) with two delay generators provide the necessary timing signals, wavelength scan waveforms, and appropriate system delays for data acquisition. All of the data was time tagged by a GPS unit that also provided position information. Additional major parameters for this flight configuration are summarized in Table 1. 
Table 1. Flight Lidar Parameters

\begin{tabular}{lc}
\hline Parameter & Value \\
\hline Seed wavelength & $1650.9 \mathrm{~nm}$ \\
Pump wavelength & $1064 \mathrm{~nm}$ \\
Laser pulse rate & $\sim 6.3 \mathrm{kHz}$ \\
Laser pulse width & $3 \mathrm{~ns}$ \\
Laser pump energy & $60 \mu \mathrm{J}$ \\
Seed power & $15 \mathrm{~mW}$ \\
OPA energy & $10 \mu \mathrm{J}$ \\
Laser divergence & $\sim 300 \mu \mathrm{rad}$ \\
Receiver diameter & $20 \mathrm{~cm}$ \\
Receiver field of view & $300 \mu \mathrm{rad}$ \\
Receiver bandpass & $800 \mathrm{pm}(\mathrm{FWHM})$ \\
Scan rate & $\sim 250 \mathrm{~Hz}$ \\
Averaging period & $1 \mathrm{~s}$ \\
Detector efficiency & $\sim 1 \%$ \\
\hline
\end{tabular}

Overall the lidar results from these flight demonstrations were consistent with the in-situ data gathered by a CRDS instrument (Picarro) flown on the same aircraft. Perfect agreement was not expected, partially because the in-situ data is taken at one point in space, while the lidar collects information over the entire column from the aircraft to the surface. A comparison of the lidar methane mixing ratio measured with the lidar and the in-situ Picarro as a function of flight time is shown in Figure 5. Additional results from this flight are detailed in Riris $e a^{42}$.

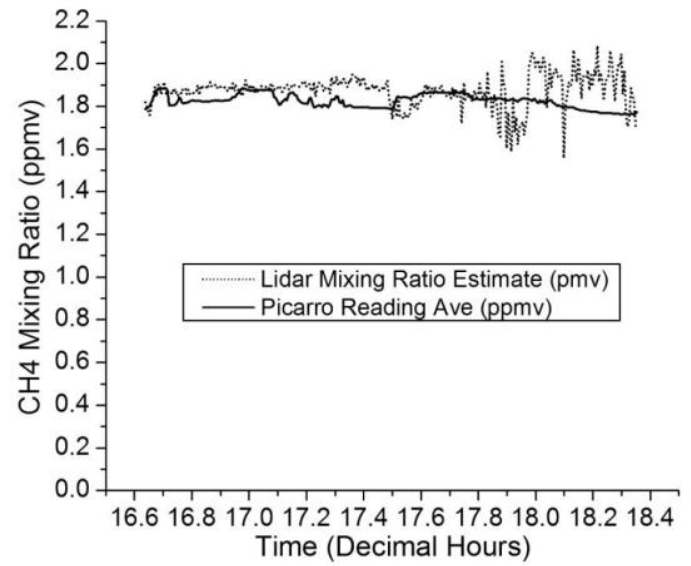

Figure 5. Comparison of the lidar methane mixing ratio with the in-situ CRDS instrument values as a function of flight time in decimal hours (UTC) for August 25th, 2011 flight. A 20 s averaging time was used.

\section{FLIGHT CONFIGURATION FOR 2015}

An updated version of the airborne methane absorption lidar will be flown on NASA's DC-8 in the fall of 2015, also over California. The general concept of operation has been proven and will not change, but there are two substantial improvements to the technology. The first is the inclusion of an OPO transmitter, and the second is the use of a new photon-counting $\mathrm{HgCdTe}$ detector, developed in collaboration with DRS technologies.

The OPA was used in 2011 because it is theoretically easier to align and tune than an OPO (because of the cavity). For the earlier flight campaign, the OPA generated $\sim 10 \mu \mathrm{J}$ at $1651 \mathrm{~nm}$, which was sufficient for an airborne campaign. However, for a space-based lidar, $\sim 300 \mu \mathrm{J}$ will be required for the desired methane absorption measurements. When the OPA was scaled to a $\sim 170 \mu \mathrm{J}$ energy, the linewidth was $\sim 10 \mathrm{GHz}(\sim 91 \mathrm{pm})$, which is too broad for accurate methane IPDA measurements. After extensive testing, it was concluded that it will be extremely difficult to scale the OPA's transmitter energy while maintaining the necessary line-widths without radical improvements in the seed laser technology. While this may be possible in the future, our current flight concept for the 2015 flight campaign incorporates an OPO transmitter in addition to the OPA.

We also plan to leverage a detector originally developed for the $\mathrm{CO} 2$ absorption lidar (ASCENDS) in collaboration with DRS Technologies. It is a HgCdTe electron Avalanche Photo Diode (e-APD) detector assembly that 
offers a wide spectral response, high dynamic range, and substantially improved sensitivity (low noise) and lifetime ${ }^{43}$. This will improve both the SNR and dynamic range of the methane absorption lidar.

\section{SUMMARY}

Atmospheric methane is the second most important anthropogenic greenhouse gas, and understanding current global methane trends is a difficult challenge that cannot be resolved by existing measurement networks or satellite observations. This work directly addresses the objectives of NASA's Earth Science Decadal Survey which explicitly calls for cost-effective global methane measurement technology. It additionally enables methane and water measurements with sufficient coverage, sensitivity, and precision to address pressing science questions for the carbon cycle and climate change.

Our team at GSFC has a demonstrated capability for the remote measurements of trace gases. Building on that experience and technology, we have developed OPG technology appropriate for the desired methane measurements, and have demonstrated an airborne methane IPDA absorption lidar. Our next airborne campaign, in September 2015, will

incorporate several significant upgrades with the expectation that the methane measurements will now have $1 \%$ precision (10-20 ppb).

\section{REFERENCES}

1. Intergovernmental Panel on Climate Change (IPCC), http://www.ipcc.ch/index.htm.

2. P. Bergamaschidaw, C. Frankenberg, J. F. Meirink, M. C. Krol, F. J. Dentener, T. Wagner, U. Platt, J. O. Kaplan, S. Körner, M. Heimann, E. J. Dlugokencky, and A. De Goede, "Satellite chartography of atmospheric methane from SCIAMACHY on board ENVISAT2. Evaluation based on inverse model simulations," J. Geophys. Res. Atmos. 112, D02304 (2007).

3. M. Buchwitz, R. De Beek, J. P. Burrows, H. Bovensmann, T. Warneke, J. Notholt, J. F. Meirink, A. P. H. Goede, P. Bergamaschi, S. Körner, M. Heimann, and A. Schulz, "Atmospheric methane and carbon dioxide from SCIAMACHYsatellite data: initial comparison with chemistry and transport models," Atmos. Chem. Phys. 5, 941-962 (2005).

4. C. Frankenberg, J. F. Meirink, P. Bergamaschi, A. P. H. Goede, M. Heimann, S. Körner, U. Platt, M. vanWeele, and T.Wagner, "Satellite cartography of atmospheric methane from SCIAMACHY on board ENVISAT: analysis of the years 2003 and 2004," J. Geophys. Res. 111, D07303 (2006).

5. A. Razavi, C. Clerbaux, C. Wespes, L. Clarisse, D. Hurtmans, S. Payan, C. Camy-Peyret, and P. Coheur, "Characterization of methane retrievals from the IASI space-borne sounder," Atmos. Chem. Phys. 9, 78897899 (2009).

6. T. August, D. Klaes, P. Schlussel, T. Hultberg, M. Crapeau, A. Arriaga, A. O'Carroll, D. Coppens, R. Munro, and X. Calbet, "IASI on Metop-A: operational level 2 retrievals after five years in orbit," J. Quant. Spectrosc. Radiat. Transfer 113, 1340-1371 (2012).

7. P. F. Coheur, X. Xiong, C. D. Barnet, Q. Zhuang, T. Machida, C. Sweeney, and P. K. Patra, "Mid-upper tropospheric methane in the high Northern Hemisphere: spaceborne observations by AIRS, aircraft measurements, and model simulations," J. Geophys. Res. 115, D19309 (2010).

8. X. Xiong, C. Barnet, E. Maddy, J.Wei, X. Liu, and T. S. Pagano, "Seven years' observation of mid-upper tropospheric methanefrom atmospheric infrared sounder," Remote Sens 2, 2509-2530 (2010).

9. T. Yokota, H. Oguma, I. Morino, A. Higurashi, T. Aoki, and G. Inoue, "Test measurements by a BBM of the nadir-looking SWIR FTS aboard GOSAT to monitor CO2 column density from space," Proc. SPIE 5652, 182 (2004).

10. T. Yokota, Y. Yoshida, N. Eguchi, Y. Ota, T. Tanaka, H. Watanabe, and S. Maksyutov, "Global concentrations of CO2 and CH4 retrieved from GOSAT: first preliminary results," Sci. Online Lett. Atmos. 5, 160-163 (2009).

11. I. Morino, O. Uchino, M. Inoue, Y. Yoshida, T. Yokota, P. O. Wennberg, G. C. Toon, D. Wunch, C. M. Roehl, J. Notholt, T. Warneke, J. Messerschmidt, D. W. T. Griffith, N. M. Deutscher, V. Sherlock, B. Connor, J. Robinson, R. Sussmann, and M. Rettinger, "Preliminary validation of column-averaged volume mixing ratios of carbon dioxide and methane retrieved from GOSAT short-wavelength infrared spectra," Atmos.Meas. Tech. 4, 1061-1076 (2011). 
12. Y. Yoshida,O. Yoshifumi, E. Nawo, K. Nobuhiro, N. Koji, T. Ha, M. Isamu, and Y. Tatsuya, "Retrieval algorithm for $\mathrm{CO} 2$ and $\mathrm{CH} 4$ column abundances from short-wavelength infrared spectral observations by the Greenhouse Gases Observing Satellite," Atmos. Meas. Tech. 4, 717-734 (2011).

13. J. Mao and S. R. Kawa, "Sensitivity studies for space-based measurement of atmospheric total column carbon dioxide by reflected sunlight," Appl. Opt. 43, 914-927 (2004).

14. I. Aben, O. Hasekamp, and W. Hartmann, "Uncertainties in the space-based measurements of CO2 columns due to scattering in the Earth's atmosphere," J. Quant. Spectrosc. Radiat. Transfer 104, 450-459 (2007).

15. E. S. Maddy, C. D. Barnet, M. Goldberg, C. Sweeney, and X. Liu, "CO2 retrievals from the atmospheric infrared sounder: methodology and validation,” J. Geophys. Res. 113, D11301 (2008).

16. E. J. Dlugokencky, S. Houweling, L. Bruhwiler, K. A. Masarie, P. M. Lang, J. B. Miller, and P. P. Tans, "Atmospheric methane levels off: temporary pause or a new steady state," Geophys. Res. Lett. 30, 1-4 (2003).

17. E. J. Dlugokencky, L. Bruhwiler, J.W. C. White, L. K. Emmons, P. C. Novelli, S. A. Montzka, K. A. Masarie, P. M. Lang, A. M. Crotwell, J. B. Miller, and L. V. Gatti, "Observational constraints on recent increases in the atmospheric CH4 burden," Geophys. Res. Lett. 36, L18803 (2009).

18. K. Kvenvolden, "Methanehydrate: a major reservoir of carbon in the shallow geosphere?," Chem. Geol. 71, 4151 (1988).

19. F. Keppler, J. T. G. Hamilton, M. Bra, and T. Roeckmann, "Methane emissions from terrestrial plants under aerobic conditions," Nature 439, 187-191 (2006).

20. T. R. Christensen, T. Johansson, H. J. Akerman, M. Mastepanov, N. Malmer, T. Friborg, P. Crill, and B. H. Vensson, "Thawing sub-arctic permafrost: effects on vegetation and methane emissions," Geophys. Res. Lett. 31, L04501 (2004).

21. K. M. W. Anthony, P. Anthony, G. Grosse, and J. Chanton, "Geologic methane seeps along boundaries of Arctic permafrost thaw and melting glaciers," Nat. Geosci. 5, 419-426 (2012).

22. E. Kort, S. Wofsy, B. Daube, M. Diao, J. Elkins, R. Gao, E. Hintsa, D. Hurst, R. Jimenez, F. Moore, J. Spackman, and M. Zondio, "Atmospheric observations of Arctic Ocean methane emissions up to $82^{\circ}$ north," Nat. Geosci. 5, 318-321 (2012).

23. J. Houghton, Y. Ding, D. J. Griggs, M. Noguer, P. J. van der Linden, X. Dai, K. Maskell, and C. A. Johnson, eds., Climate Change 2001: The Scientific Basis (Cambridge University, 2001).

24. NASA, "NASA ASCENDS Workshop," http://cce.nasa.gov/ascends_2012/index.html.

25. K. Numata, H. Riris, S. Li, S.Wu, S. R. Kawa, M. Krainak, and J. Abshire, "Ground demonstration of a trace gas lidar based on optical parametric amplifiers," J. Appl. Remote Sens. 6, 063561 (2012).

26. H. Riris, S. Li, K. Numata, S. Wu, J. Burris, A. W. Yu, M. Krainak, and J. B. Abshire, "Methane measurements using optical parametric technology," American Geophysical Union, Fall Meeting 2009 (American Geophysical Union, 2009), abstract no. A41C-0106.

27. D. G. Murdock, S. V. Stearns, R. T. Lines, D. Lenz, D. M. Brown, and C. R. Philbrick, "Applications of realworld gas detection: airborne natural gas emission lidar (ANGEL) system," J. Appl. Remote Sens. 2, 023518 (2008).

28. A. Minato, M. A. Joarder, S. Ozawa, M. Kadoya, and N. Sugimoto, "Laser long-path absorption lidar technique for measuring methane using gas correlation method," Jpn. J. Appl. Phys. 38, 6130-6132 (1999).

29. Y. Kamali, J. F. Daigle, F. Théberge, M. Châteauneuf, A. Azarm, Y. Chen, C. Marceau, Z.-D. Sun, J. Bernhardt, S. C. Lessard, F. Lessard, G. Roy, J. Dubois, and S. L. Chin, "Remote sensing of trace methane using mobile femtosecond laser system of T\&T Lab," Opt. Commun. 282, 2062-2065 (2009).

30. M. J. T. Milton, T. D. Gardiner, T. Molero, and J. Galech, "Injection-seeded optical parametric oscillator for range resolved DIAL measurements of atmospheric methane," Opt. Commun. 142, 153-160 (1997).

31. E. R. Crosson, "A cavity ring-down analyzer for measuring atmospheric levels of methane, carbon dioxide, and water vapour," Appl. Phys. B 92, 403-408 (2008).

32. C. Webster, "Measuring methane and its isotopes $12 \mathrm{CH} 4,13 \mathrm{CH} 4$, and $\mathrm{CH} 3 \mathrm{D}$ on the surface of Mars with in situ laser spectroscopy," Appl. Opt. 44, 1226-1235 (2005).

33. S. Wright, G. Duxbury, and N. Langford, "A compact quantumcascade laser based spectrometer for monitoring the concentrations of methane and nitrous oxide in the troposphere," Appl. Phys. B 85, 243-249 (2006).

34. G. Ehret, C. Kiemle, M. Wirth, A. Amediek, A. Fix, S. Houweling, Appl. Phys. B 90, 593-608 (2008)

35. X. Sun, J. Abshire, Opt. Express 20, 21291-21304 (2012)

36. J. Abshire, H. Riris, C. Weaver, J. Mao, G. Allan, W. Hasselbrack, E. Browell, Appl. Opt. 52, 4446-4461 (2013). 
37. K. Numata, J. R. Chen, S. T. Wu, J. B. Abshire, and M. A. Krainak, "Frequency stabilization of distributedfeedback laser diodes at $1572 \mathrm{~nm}$ for lidar measurements of atmospheric carbon dioxide," Appl. Opt. 50, 1047 (2011).

38. G. Ehret, A. Fix, V. Veiß, G. Poberaj, T. Baumert, Appl. Phys. B 67, 427-431 (1998)

39. A. Amediek, A. Fix, M. Wirth, G. Ehret, Appl. Phys. B 92, 295-302 (2008)

40. D. Sakaizawa, C. Nagasawa, T. Nagai, M. Abo, Y. Shibata, M. Nakazato, T. Sakai, Appl. Opt. 48, 748-757 (2009)

41. K. Numata, S. Wu, and H. Riris, "Fast-switching methane lidar transmitter based on a seeded optical parametric oscillator," Appl. Phys. B, (Feb 2014).

42. H. Riris, K. Numata, S. Li, S. Wu, A. Ramanathan, M.Dawsey, J. Mao, R. Kawa, and J. Abshire, “Airborne measurements of atmospheric methane column abundance using a pulsed integrated-path differential absorption lidar," Appl. Optics, 51:34, 8296-8305 (2012).

43. J. Beck, et al., Proc. SPIE 8739, Sensors and Systems for Space Applications VI, 87390V (May 21, 2013); doi:10.1117/12.2018083. 